Article

\title{
Biochemical Characterization of a Novel Endo-1,3- $\beta$-Glucanase from the Scallop Chlamys farreri
}

\author{
Zhijian Li ${ }^{1}$, Weizhi Liu ${ }^{1,2}$ and Qianqian Lyu ${ }^{1,2, *}$ \\ 1 MOE Key Laboratory of Marine Genetics and Breeding, College of Marine Life Sciences, \\ Ocean University of China, Qingdao 266003, China; lizhijian11@foxmail.com (Z.L.); \\ liuweizhi@ouc.edu.cn (W.L.) \\ 2 Laboratory for Marine Biology and Biotechnology, Qingdao National Laboratory for \\ Marine Science and Technology, Qingdao 266235, China \\ * Correspondence: lyuqianqian@ouc.edu.cn
}

Received: 26 August 2020; Accepted: 13 September 2020; Published: 16 September 2020

\begin{abstract}
Endo-1,3- $\beta$-glucanases derived from marine mollusks have attracted much attention in recent years because of their unique transglycosylation activity. In this study, a novel endo-1,3- $\beta$-glucanase from the scallop Chlamys farreri, named $\mathrm{L}_{\mathrm{cf}}$, was biochemically characterized. Unlike in earlier studies on marine mollusk endo-1,3- $\beta$-glucanases, $\mathrm{L}_{\mathrm{cf}}$ was expressed in vitro first. Enzymatic analysis demonstrated that $\mathrm{L}_{\mathrm{cf}}$ preferred to hydrolyze laminarihexaose than to hydrolyze laminarin. Furthermore, $\mathrm{L}_{\mathrm{cf}}$ was capable of catalyzing transglycosylation reactions with different kinds of glycosyl acceptors. More interestingly, the transglycosylation specificity of $\mathrm{L}_{\mathrm{cf}}$ was different from that of other marine mollusk endo-1,3- $\beta$-glucanases, although they share a high sequence identity. This study enhanced our understanding of the diverse enzymatic specificities of marine mollusk endo-1,3- $\beta$-glucanases, which facilitated development of a unique endo-1,3- $\beta$-glucanase tool in the synthesis of novel glycosides.
\end{abstract}

Keywords: endo-1,3- $\beta$-glucanases; marine mollusk; transglycosylation; laminarin

\section{Introduction}

Endo-1,3- $\beta$-glucanases (EC 3.2.1.39), also called laminarinases, can specifically hydrolyze $\beta$-1,3-glycosidic bonds in laminarin, whereas they hardly hydrolyze mix-linked $\beta-1,3-1,4$-glycosidic bonds in lichenin and cereal $\beta$-glucans [1]. The products of hydrolyzing laminarin, glucooligosaccharides, have been demonstrated to have a variety of biological activities, such as anti-diabetic activity [2], stimulating leukocytes to induce the production of cytokines [3], modulating lipid metabolism and intestinal microflora [4], and activating defense responses of plant cells $[5,6]$. Therefore, suitable endo-1,3- $\beta$-glucanases are determinants for the enzymatic preparation of well-defined glucooligosaccharides. In addition to their hydrolytic activity, some endo- 1,3 - $\beta$-glucanases exhibit transglycosylation activity, by which $\beta$-1,3-oligosaccharides (glycosyl donors) are transferred to hydroxyl compounds (glycosyl acceptors), generating new glycosidic bonds [7]. The glycosyl acceptors include monosaccharides, oligosaccharides, and other hydroxyl-containing compounds, such as alcohols and amino acids [1]. New bonds can be synthesized during transglycosylation, which is important for the synthesis of new glycosides [8]. Numerous oligosaccharides, glycolipids, and glycoproteins with novel biological activities have been discovered through glycosyltransferase synthesis [9]. Therefore, research on glycosidases has attracted increasing attention in recent years.

Endo-1,3- $\beta$-glucanases are widely distributed in archaea [10], bacteria [11-13], viruses [14], and eukaryota [15-18]. According to the amino acid sequences, endo-1,3- $\beta$-glucanases are classified 
into seven glycoside hydrolase (GH) families: GH16, GH17, GH55, GH64, GH81, GH128, and GH152. These endo-1,3- $\beta$-glucanases function in various life processes, such as the degradation of polysaccharides for energy utilization, cell development, and cell differentiation. For example, the $\beta$-1,3-glucanase-related protein from the red swamp crayfish, Procambarus clarkia, can be induced by bacteria, which is an important factor in the immune response [19]. The killer toxin secreted by the yeast Wickerhamomyces anomalus has also exhibited $\beta$-glucanase activity, which has potential for use in the symbiotic control of malaria [20]. Marine organisms are important sources for deriving new endo-1,3- $\beta$-glucanases [1], especially the digestive tracts of marine invertebrates, which are usually composed of various enzymes related to polysaccharide utilization. More interestingly, the endo-1,3- $\beta$-glucanases from marine organisms have demonstrated increased transglycosylation ability relative to those from terrestrial sources [1]. To date, a total of ten endo-1,3- $\beta$-glucanases have been determined to exhibit transglycosylation activity, two of which belong to the GH17 family [18,21], and the other eight belonging to the GH16 family. Among these eight endo-1,3- $\beta$-glucanases, one is derived from marine bacteria [22], and the remaining are all derived from marine mollusks [16,17,23-27]. Due to the presence of both hydrolytic activity and transglycosylation activity, marine mollusk endo-1,3- $\beta$-glucanases have distinctive advantages in the preparation of novel, useful glucooligosaccharides or glucans. For instance, soluble $\beta-1,3-1,6$-glucan obtained by transglycosylation of laminarin, using the endo-1,3- $\beta$-glucanase derived from the scallop Chlamys albidus, exhibits high immune stimulation, and bacteriostatic and antitumor activities [16]. The reported marine mollusk endo-1,3- $\beta$-glucanases have shown another interesting feature: these enzymes exhibit diverse specificities, and even their amino acid sequences have a high degree of similarity [1]. To reveal their unique specificities, more research on marine mollusk endo-1,3- $\beta$-glucanases is required.

Previously, in combination with proteomic analysis and the use of the whole-genome database, we identified a novel endo-1,3- $\beta$-glucanase from a hepatopancreatic extract of the Zhikong scallop (Chlamys farreri) [28]. In this study, the gene of the endo-1,3- $\beta$-glucanase (named $\mathrm{L}_{\mathrm{cf}}$ ) was cloned and expressed using the Brevibacillus (Bacillus brevis) expression system. After protein purification, the catalytic properties of $\mathrm{L}_{\mathrm{cf}}$ were characterized, and the transglycosylation specificity was determined. This study enhanced our understanding of the marine mollusk endo-1,3- $\beta$-glucanases.

\section{Results and Discussion}

\subsection{Sequence Alignment between $L_{c f}$ and Endo-1,3- $\beta$-Glucanases from GH16}

Sequence alignment between $\mathrm{L}_{\mathrm{cf}}$ and six characterized GH16 endo-1,3- $\beta$-glucanases was performed using ClustalW Multiple Alignment. These enzymes were derived from the marine mollusk Mizuhopecten yessoensis [29], terrestrial arthropod Tenebrio molitor [30], marine hot spring bacterium Thermotoga maritima [12], bacterium Zobellia galactanivorans [31] isolated from marine red algae, terrestrial bacterium Cellulosimicrobium cellulans [11], and terrestrial fungus Ustilago esculenta [32]. Sequence alignment indicated that $\mathrm{L}_{\mathrm{cf}}$ shared $87.4 \%$ sequence identity with the endo- $1,3-\beta$-glucanases derived from the marine mollusk Mizuhopecten yessoensis. In contrast, $\mathrm{L}_{\mathrm{cf}}$ shared only $23.6-41.3 \%$ sequence identity with the other endo-1,3- $\beta$-glucanases (Figure 1). This was consistent with the conclusion that endo-1,3- $\beta$-glucanases derived from marine mollusks have high homology $[15,24]$. 


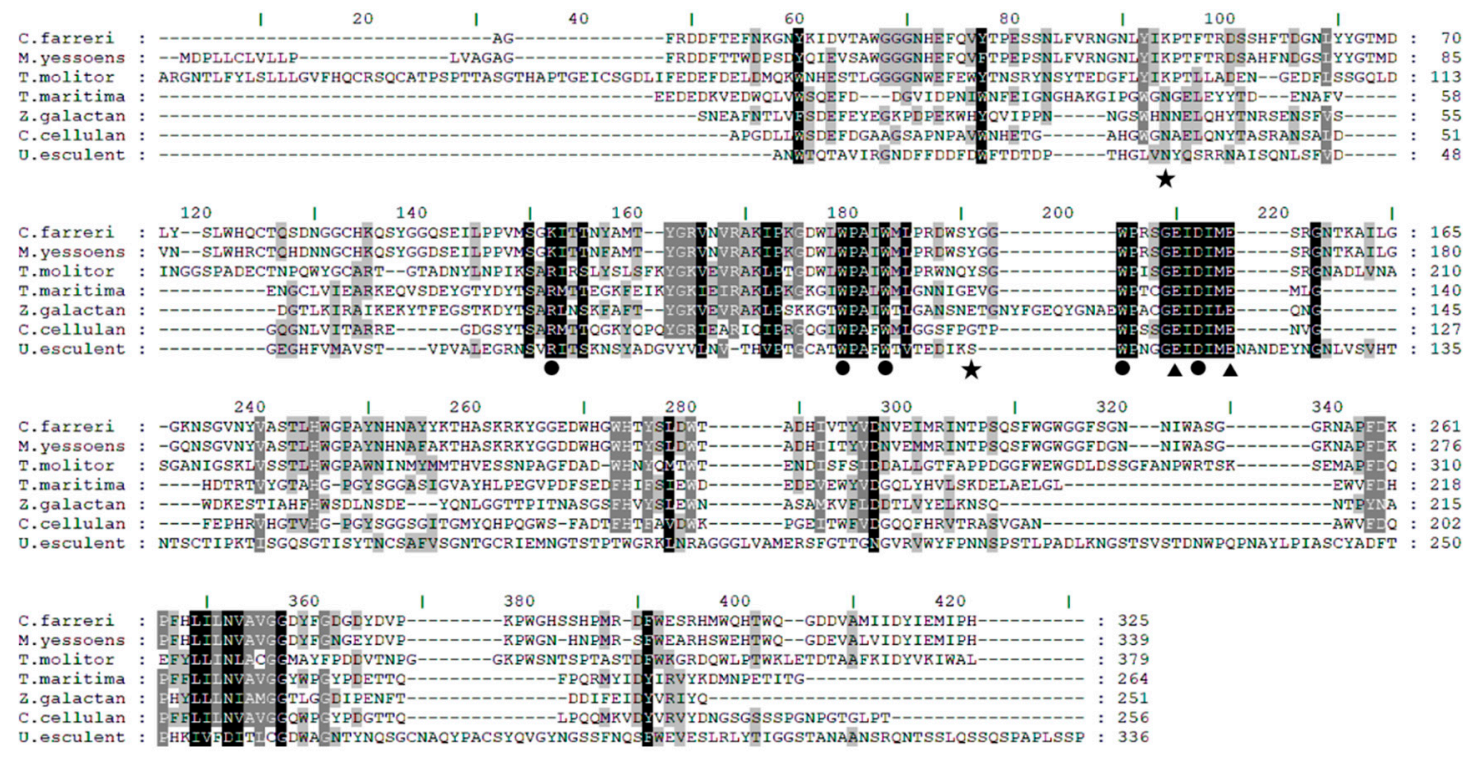

Figure 1. Sequence alignment of characterized GH16 $\beta$-1,3-glucanases from different organisms. The identical residues are highlighted in black, and similar residues are shaded in gray. The two key catalytic residues conserved in GH16 endo-1,3- $\beta$-glucanases are marked with triangles. For $\beta$-glucanase $\mathrm{ZgLamA}_{\mathrm{GH} 16}$, the residues involved in substrate binding are marked with closed circles and stars. The residues marked with closed circles are conserved in these endo-1,3- $\beta$-glucanases, but the two residues marked with stars are not conserved. The GeneBank accession numbers of the present endo-1,3- $\beta$-glucanases are: Chlamys farreri: AMN92714.1 $\left(\mathrm{L}_{\mathrm{cf}}\right)$; Mizuhopecten yessoensis: AAW34372.1; Tenebrio molitor: ACS36221.1; Thermotoga maritima: AAD35118.1; Zobellia galactanivorans: CAZ96583.1 (PDB ID: 4BOW); Cellulosimicrobium cellulans: AAC38290.1; and Ustilago esculenta: BAM29293.1.

Additionally, sequence alignment demonstrated the key residues involved in catalytic reactions and substrate binding. A previous study had demonstrated that two conserved glutamates in the pattern EXDX $(X) E$ function in the catalytic reaction were a nucleophile and general acid/base, respectively [31]. In $\mathrm{L}_{\mathrm{cf}}$, the equivalent to the nucleophile was Glu150, whereas the general acid/base was Glu155 (Figure 1). In addition, the structures of the $\beta$-glucanase $\mathrm{ZgLamA}_{\mathrm{GH} 16}$ complex with oligo substrates has previously been solved (PDB ID: 4BOW) [31], providing knowledge of key residues involved in substrate binding. The complex structures of $\mathrm{ZgLamA}_{\mathrm{GH} 16}$ identified seven residues involved in substrate binding, five of which are conserved based on the sequence alignment. In $\mathrm{L}_{c f}$, the equivalent to the conserved residues were Lys105, Trp130, Trp134, Asp152, and Trp145 (Figure 1).

\subsection{Expression and Purification of $L_{c f}$}

In a previous study, direct extraction of the enzyme from the digestive organs of marine mollusks was the general method used for collecting endo-1,3- $\beta$-glucanases [24-26]. However, the isolation of endo-1,3- $\beta$-glucanases from digestive organs is not only time-consuming, but is also limited by the source of marine mollusks. Therefore, we carried out the expression of $\mathrm{L}_{\mathrm{cf}}$ in vitro using the Escherichia coli expression system and Bacillus brevis expression system. Although the recombinant proteins were detected in the supernatant of the cell lysis, they did not exhibit enzymatic activity, suggesting the occurrence of incorrect protein folding in the expression of $\mathrm{L}_{\mathrm{cf}}$ in the E. coli expression system. Fortunately, recombinant $\mathrm{L}_{\mathrm{cf}}$ with hydrolytic activity was detected successfully in the fermentation broth of Bacillus brevis. After a three-step purification, including ammonium sulfate salting out, hydrophobic chromatography, and ion exchange chromatography, about $12 \mathrm{mg}$ of $\mathrm{L}_{\mathrm{cf}}$ was extracted from $1 \mathrm{~L}$ of fermentation broth of Bacillus brevis. The molecular weight of $\mathrm{L}_{\mathrm{cf}}$ was about $37 \mathrm{kDa}$, as shown in Figure 2. 


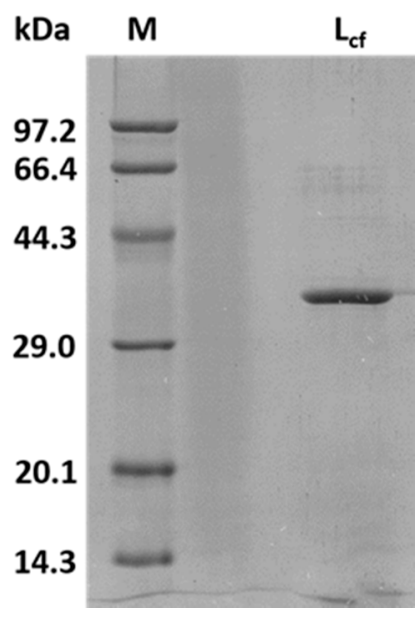

Figure 2. SDS-PAGE analysis of the purified $\mathrm{L}_{\mathrm{cf}}$.

Through the Bacillus brevis expression system, $\mathrm{L}_{\mathrm{cf}}$ was expressed in vitro successfully, providing a more convenient method for the extraction of marine mollusk endo-1,3- $\beta$-glucanases. In addition, this method may facilitate performing further structural research, which will be important for understanding the unique transglycosylation activity of marine mollusk endo- $1,3-\beta$-glucanases.

\subsection{Enzymatic Characterization of $L_{c f}$}

A hydrolytic activity assay at various $\mathrm{pH}$ values indicated that $\mathrm{L}_{\mathrm{cf}}$ exhibited the maximum hydrolytic activity at pH 6.0 (Figure 3a). Additionally, the assay at different temperatures demonstrated that the optimal temperature for $\mathrm{L}_{\mathrm{cf}}$ was $44^{\circ} \mathrm{C}$ (Figure $3 \mathrm{~b}$ ). When the incubation temperature was higher than $45^{\circ} \mathrm{C}$, the hydrolytic activity of $\mathrm{L}_{\mathrm{cf}}$ decreased significantly (Figure 3c). The enzymatic activity of $\mathrm{L}_{\mathrm{cf}}$ was abolished after pre-incubation of $\mathrm{L}_{\mathrm{cf}}$ at $60^{\circ} \mathrm{C}$ and $70{ }^{\circ} \mathrm{C}$ (Figure 3c). In addition, $\mathrm{L}_{\mathrm{cf}}$ retained approximately $25 \%$ of the enzymatic activity with the addition of EDTA (Figure $3 \mathrm{~d}$ ), suggesting that metal ions might influence the enzymatic activity of $\mathrm{L}_{\mathrm{cf}}$, but are not essential for $\mathrm{L}_{\mathrm{cf}}$. Notably, the enzymatic activity of $\mathrm{L}_{\mathrm{cf}}$ was increased by approximately three times in the presence of $\mathrm{Mn}^{2+}$. The enzymatic activity of $\mathrm{L}_{\mathrm{cf}}$ was also enhanced by $\mathrm{Fe}^{3+}$, and the addition of $\mathrm{Ca}^{2+}$ seemed not to affect the enzymatic activity of $\mathrm{L}_{\mathrm{cf}}$. However, the enzymatic activity of $\mathrm{L}_{\mathrm{cf}}$ was inhibited in the presence of $\mathrm{Mg}^{2+}, \mathrm{Cu}^{2+}$, and $\mathrm{Zn}^{2+}$, especially in the presence of $\mathrm{Cu}^{2+}$ (Figure 3d).

Furthermore, the kinetic parameters of $\mathrm{L}_{\mathrm{cf}}$ towards laminarin were measured. The specific activity for $\mathrm{L}_{\mathrm{cf}}$ was $1.67 \mathrm{U} / \mathrm{mg}$, and its $K_{m}$ and $K_{\text {cat }}$ values were $10.27 \mathrm{mg} / \mathrm{mL}$ and $1230.64 \mathrm{~S}^{-1}$, respectively. 


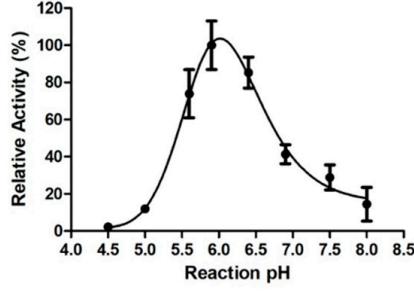

(a)

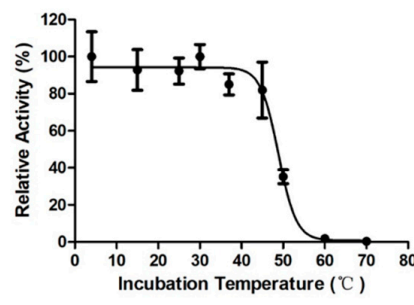

(c)

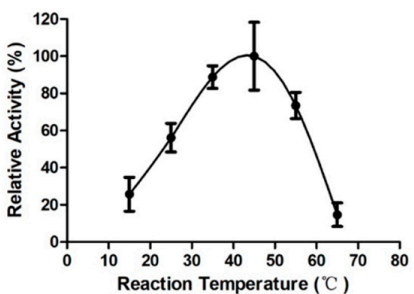

(b)

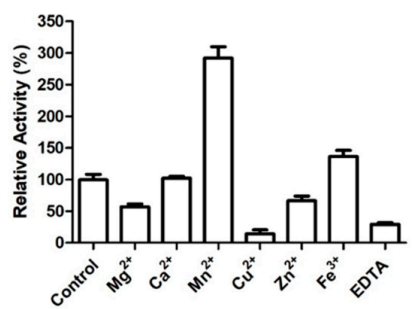

(d)

Figure 3. Effect of $\mathrm{pH}$, temperature, and metal ions on $\mathrm{L}_{\mathrm{cf}}$ enzymatic activity and the thermostability of $\mathrm{L}_{\mathrm{cf}}$. (a) The effect of $\mathrm{pH}$ on $\mathrm{L}_{\mathrm{cf}}$ activity. The optimal $\mathrm{pH}$ was determined by measuring the enzymatic activity of $\mathrm{L}_{\mathrm{cf}}$ at $\mathrm{pH} 4.5,5.0,5.6,5.9,6.4,6.9,7.5$, and 8.0, at $37^{\circ} \mathrm{C}$. (b) The effect of temperature on $\mathrm{L}_{\mathrm{cf}}$ activity. The optimal temperature was determined by measuring the enzymatic activity of $\mathrm{L}_{\mathrm{cf}}$ at $15{ }^{\circ} \mathrm{C}$, $25^{\circ} \mathrm{C}, 35^{\circ} \mathrm{C}, 45^{\circ} \mathrm{C}, 55^{\circ} \mathrm{C}$, and $65^{\circ} \mathrm{C}$. (c) The thermostability of $\mathrm{L}_{\mathrm{cf}}$. The activity of $\mathrm{L}_{\mathrm{cf}}$ was measured at $37^{\circ} \mathrm{C}$ after pre-incubation at $4-70{ }^{\circ} \mathrm{C}$ for $15 \mathrm{~min}$. (d) The effect of metal ions on $\mathrm{L}_{\mathrm{cf}}$ activity. The activity of $\mathrm{L}_{\mathrm{cf}}$ was measured in the presence of various metal ions $(5 \mathrm{mM})$.

\subsection{Analyses of Hydrolytic Products and Transglycosylation Products}

To test the hydrolytic products of $\mathrm{L}_{\mathrm{cf}}$, Thin layer chromatography (TLC) analysis was carried out. As shown in Figure 4, both the laminarin and the laminarinexaose were hydrolyzed into several oligomers, confirming that $\mathrm{L}_{\mathrm{cf}}$ acted in an endo-type mode. However, different cleavage efficiencies were observed. $\mathrm{L}_{\mathrm{cf}}$ showed a more efficient cleavage rate toward laminarinexaose. After reaction for $1 \mathrm{~min}$, hydrolysis products with a degree of polymerization (Dp) 1-5 were generated. These oligomeric products were further hydrolyzed into monomers and dimers as end-products (Figure 4). In contrast, laminarin was not hydrolyzed completely (Figure 4). Considering the fact that laminarins from Laminaria digitate have a branch degree of $7.68 \%$, and these branches contain about $9.51 \% \beta-1,6$-glycosidic bonds [33], the more complex structure and the longer chain of laminarins might lead to a lower cleavage rate for $\mathrm{L}_{\mathrm{cf}}$.

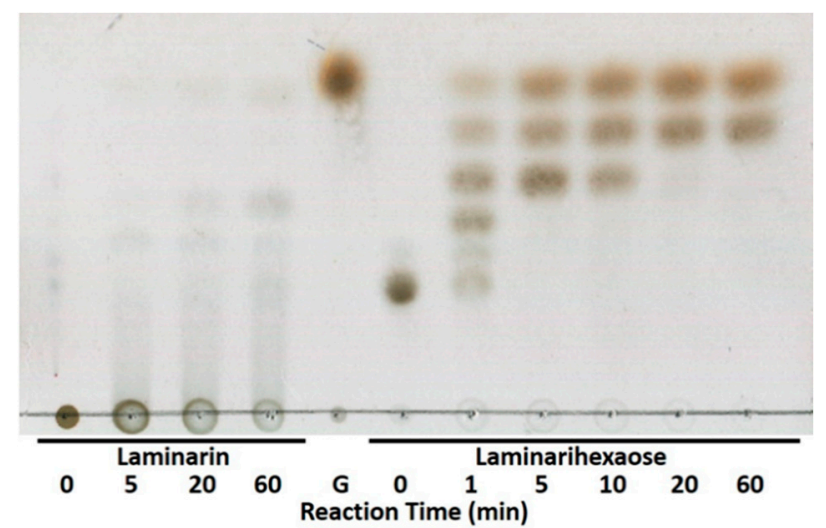

Figure 4. Thin layer chromatography (TLC) analysis of the hydrolysis products of laminarin and laminarihexaose using glucose $(\mathrm{G})$ as control. 
To explore the transglycosylation specificity of $\mathrm{L}_{\mathrm{cf}}$, the transglycosylation products were analyzed by MS. Laminarin has usually been selected as the substrate for transglycosylation reactions in previous studies $[16,23,24]$. However, $\mathrm{L}_{\mathrm{cf}}$ showed a more efficient cleavage rate toward laminarinexaose than laminarin, as described above. Accordingly, the substrate we used in the transglycosylation reaction was laminarinexaose. Furthermore, the acceptors contained monosaccharides (methyl $\alpha$-D-glucopyranoside and methyl $\beta$-D-glucopyranoside), alcohol (ethanol), polyols (glycerol and D-sorbitol), and amino acids with hydroxyl side chains (L-serine). As shown in Figure $5 \mathrm{a}$, the methylated disaccharide, trisaccharide, and tetrasaccharide were detected in the presence of methyl $\alpha$-D-glucopyranoside or methyl $\beta$-D-glucopyranoside, suggesting that the donors of glycosylation were glucose, laminaribiose, and laminaritriose. Transglycosylation products were also observed in the presence of the other acceptors (Figure $5 \mathrm{c}-\mathrm{f}$ ). In the presence of glycerol, five transglycosylation products were generated (Figure $5 \mathrm{c}$ ). Similar to methyl $\alpha$-D-glucopyranoside or methyl $\beta$-D-glucopyranoside, three transglycosylation products were observed in the presence of D-sorbitol (Figure 5d). However, only one transglycosylation product was detected using ethanol or L-serine as the acceptor (Figure $5 \mathrm{e}, \mathrm{f}$ ). Besides transglycosylation products, hydrolytic products, including glucose, G2, G3, G4, and G5, were detected. The $\mathrm{m} / \mathrm{z}$ of each product in ESI-MS (+) is shown in Table 1.

The transglycosylation activity of O-glycoside hydrolases can be used for the synthesis of new glycosides, which has potential for the development of novel drugs and functional foods. For example, transglycosylation may function in the synthesis of glycosylated therapeutic antibodies and glycoside-specific antibody-drug conjugates [34]. Therefore, the diverse transglycosylation specificities of endo-1,3- $\beta$-glucanases have attracted much attention. As described above, $\mathrm{L}_{\mathrm{cf}}$ exhibited transglycosylation activity towards different kinds of acceptors, which facilitated the synthesis of novel glycosides. Additionally, in the transglycosylation reaction catalyzed by the endo-1,3- $\beta$-glucanase from Mizuhopecten yessoensis, only a sorbitol-Glc 3 product was detected when using D-sorbitol as an acceptor [24]. However, three transglycosylation products linked with sorbitol were observed after the transglycosylation reaction catalyzed by $\mathrm{L}_{\mathrm{cf}}$ (Figure $5 \mathrm{~d}$ ). These findings demonstrated that the two endo-1,3- $\beta$-glucanases from mollusks exhibit different transglycosylation specificities, although they share a high sequence identity. The unique transglycosylation activity of $\mathrm{L}_{\mathrm{cf}}$ towards sorbitol facilitates the development of glycoconjugates with intestinal functions, and noncariogenic sugars [35]. In sum, this study provided insights into novel endo- $1,3-\beta$-glucanases from marine mollusks, enhancing our understanding of the diverse enzymatic specificities of marine mollusk endo- $1,3-\beta$-glucanases. 


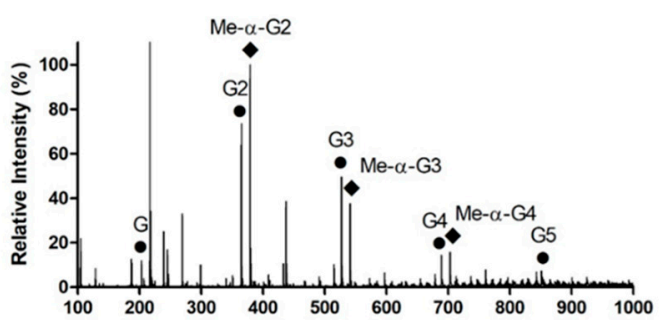

(a)

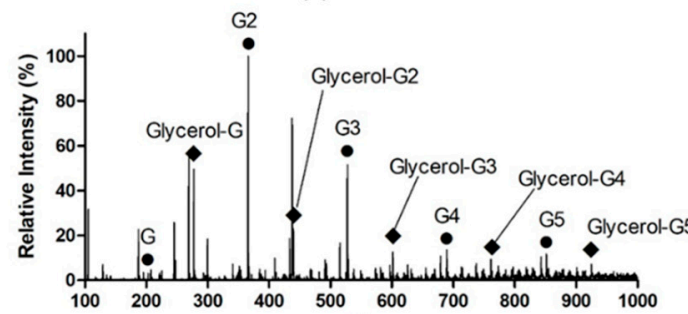

(c) ${ }^{\mathrm{m} / \mathrm{z}}$

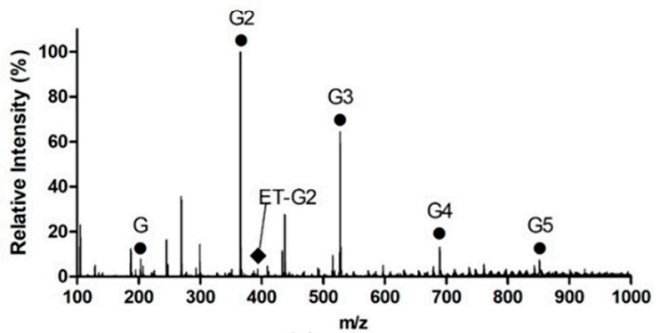

(e)

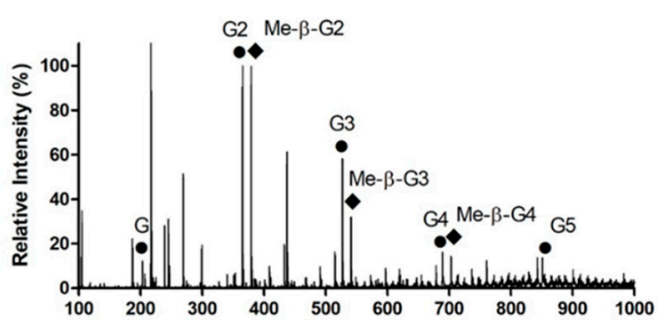

(b)

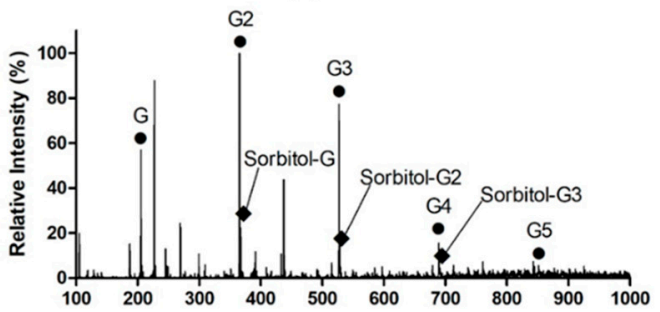

(d) ${ }^{\mathrm{m} / \mathrm{2}}$

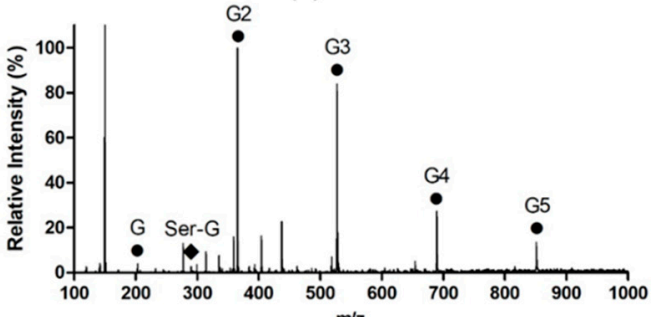

(f)

Figure 5. ESI-MS spectrometry analysis of the transglycosylation products. Laminarihexaose was used as the substrate or the donor. A total of six acceptors were tested in the transglycosylation reaction, including methyl $\alpha$-D-glucopyranoside (a), methyl $\beta$-D-glucopyranoside (b), glycerol (c), D-sorbitol (d), ethanol (e), and L-Serine (f). The $m / z$ of the ion peaks $[\mathrm{M}+\mathrm{Na}]^{+}$of the products are indicated by dots (hydrolysis products) and rhombuses (transglycosylation products). The $m / z$ of the products are summarized in Table 1.

\section{Materials and Methods}

\subsection{RNA Extraction and Gene Cloning}

The scallops were purchased from the Nanshan seafood market in Qingdao. The hepatopancreas was dissected by hand from the scallop viscera. Then, the hepatopancreas was ground into powder in liquid nitrogen. Next, the total RNA was extracted from the powder using the Mollusc RNA Kit (Omega Bio-tek, Norcross, GA, USA). A cDNA library of scallop hepatopancreas was constructed by reverse transcription, using the extracted total RNA as a template (RevertAid First Strand cDNA Synthesis Kit, Thermo Fisher Scientific, Waltham, MA, USA). Using the cDNA library as a template, a full-length gene of $\mathrm{L}_{\mathrm{cf}}$ without the signal peptide was cloned using the following primers: a forward primer (5'-CGGGATCCGCAGGCTTCCGTGACGATTTCAC-3') and a reverse primer (5'-CCGCTCGAGTCAATGAGGTATCATCTCTATGTAATC-3'). Target gene fragments were collected using the Gel Extraction Kit (Omega Bio-tek, Norcross, GA, USA), and ligated into the shuttle vector pNCMO2 (Takara, Dalian, China) using the restriction enzymes BamHI and XhoI. Then, the ligation solution was transformed into E. coli JM109. Expression plasmids were extracted using the Plasmid Mini Kit (Omega Bio-tek, Norcross, GA, USA). 
Table 1. Summary of $\mathrm{m} / \mathrm{z}$ of the ion peaks $[\mathrm{M}+\mathrm{Na}]^{+}$corresponding to hydrolysis and transglycosylation products.

\begin{tabular}{ccc}
\hline Symbol & Compound & $m / z$ \\
\hline G & Glucose & 203.2 \\
G3 & Laminaribiose & 365.4 \\
G4 & Laminaritriose & 527.3 \\
G5 & Laminaritetraose & 689.3 \\
Me- $\alpha$-G2 & Laminaripentaose & 851.2 \\
Me- $\alpha$-G3 & Methyl $\alpha$-D-Glc2 & 379.4 \\
Me- $\alpha-G 4$ & Methyl $\alpha$-D-Glc3 & 541.4 \\
Me- $\beta-G 2$ & Methyl $\alpha$-D-Glc4 & 703.2 \\
Me- $\beta-G 3$ & Methyl $\beta-D-G l c 2$ & 379.4 \\
Me- $\beta-G 4$ & Methyl $\beta-D-G l c 3$ & 541.3 \\
Glycerol-G & Methyl $\beta-D-G l c 4$ & 703.2 \\
Glycerol-G2 & Glycerol-Glc1 & 227.3 \\
Glycerol-G3 & Glycerol-Glc2 & 439.4 \\
Glycerol-G4 & Glycerol-Glc3 & 601.2 \\
Glycerol-G5 & Glycerol-Glc4 & 763.2 \\
Sorbitol-G & Glycerol-Glc5 & 924.9 \\
Sorbitol-G2 & Sorbitol-Glc1 & 367.4 \\
Sorbitol-G3 & Sorbitol-Glc2 & 529.3 \\
ET-G2 & Sorbitol-Glc3 & 691.2 \\
Ser-G & Ethanol-Glc2 & 393.3 \\
\hline
\end{tabular}

\subsection{Protein Expression in Brevibacillus}

The Brevibacillus (Bacillus brevis) expression system (Takara, Dalian, China) is a prokaryotic expression system that is particularly effective in the production of secretory proteins [36]. The expression plasmids were transformed into Brevibacillus-competent cells using the new Tris-PEG (NTP) method, as described in the protocol. Brevibacillus transformant cells were grown in MTNm solid medium (glucose $10 \mathrm{~g} / \mathrm{L}$, polypeptone $10 \mathrm{~g} / \mathrm{L}$, beef powder $5 \mathrm{~g} / \mathrm{L}$, yeast extract $2 \mathrm{~g} / \mathrm{L}, \mathrm{FeSO}_{4} \cdot 7 \mathrm{H}_{2} \mathrm{O}$ $10 \mathrm{mg} / \mathrm{L}, \mathrm{MnSO}_{4} \cdot 4 \mathrm{H}_{2} \mathrm{O} 10 \mathrm{mg} / \mathrm{L}, \mathrm{ZnSO}_{4} \cdot 7 \mathrm{H}_{2} \mathrm{O} 1 \mathrm{mg} / \mathrm{L}, \mathrm{MgCl}_{2} \cdot 6 \mathrm{H}_{2} \mathrm{O} 4.1 \mathrm{~g} / \mathrm{L}$, and neomycin $10 \mathrm{mg} / \mathrm{L}$, $\mathrm{pH} 7.0$ ) at $37^{\circ} \mathrm{C}$. DNA sequencing was performed to confirm the recombinant Brevibacillus. Then, the recombinant Brevibacillus cells were cultured in TMNm liquid medium (i.e., MTNm medium without $\mathrm{MgCl}_{2}$ ) at $32{ }^{\circ} \mathrm{C}$ for $48 \mathrm{~h}$. SDS-PAGE analysis indicated that $\mathrm{L}_{\mathrm{cf}}$ was successfully secreted into the fermentation broth.

\subsection{Protein Purification}

As described above, the Brevibacillus transformant cells were cultured for $48 \mathrm{~h}$, then the fermentation broth was harvested by centrifuging at $6000 \times \mathrm{g} \mathrm{rpm}$ for $5 \mathrm{~min}$. To precipitate the enzymes, ammonium sulfate was slowly added to the fermentation broth to $60 \%$ saturation $\left(0{ }^{\circ} \mathrm{C}\right)$. After $10 \mathrm{~h}$, the precipitate was collected by centrifugation $\left(12,000 \times g, 4^{\circ} \mathrm{C}\right)$, followed by washing using ammonium sulfate solution $\left(60 \%\right.$ saturation, $\left.0{ }^{\circ} \mathrm{C}\right)$. The resulting protein was re-dissolved in a Tris- $\mathrm{HCl}$ buffer $(20 \mathrm{mM}$, $\mathrm{pH} 7.5)$ containing $15 \%$ saturation $\left(0^{\circ} \mathrm{C}\right)$ ammonium sulfate. Then, the protein was loaded onto Phenyl Sepharose beads (GE Healthcare, Boston, MA, USA), which were washed and eluted using Tris- $\mathrm{HCl}$ buffer $(20 \mathrm{mM}, \mathrm{pH} 7.5)$ containing $15-0 \%$ saturation $\left(0{ }^{\circ} \mathrm{C}\right)$ ammonium sulfate. After purification by the Phenyl Sepharose beads, the resulting protein was dialyzed into a sodium acetate buffer (50 mM, pH 5.0). Next, the protein was loaded onto CM Sepharose beads (GE Healthcare), which were washed and eluted using sodium acetate buffer (50 mM, pH 5.0) containing $0-0.5 \mathrm{M} \mathrm{NaCl}$. 


\subsection{Hydrolytic Activity Assay}

The hydrolytic activity of $\mathrm{L}_{\mathrm{cf}}$ was determined by the modified DNS method [37]. The reaction mixture $(200 \mu \mathrm{L})$, containing $0.1 \%(w / w)$ laminarin from Laminaria digitate dissolved in sodium acetate buffer $\left(50 \mathrm{mM}\right.$, pH 5.6) and $20 \mu \mathrm{L}$ purified $\mathrm{L}_{\mathrm{cf}}$, was incubated for $20 \mathrm{~min}$ at $37^{\circ} \mathrm{C}$. Then, $150 \mu \mathrm{L}$ DNS was added to terminate the reaction. The resulting mixture was boiled for $5 \mathrm{~min}$ at $100{ }^{\circ} \mathrm{C}$ and measured at $520 \mathrm{~nm}$. One unit (1 U) of hydrolytic activity was defined as the amount of enzyme required to produce the reducing sugar equivalent to $1 \mu \mathrm{mol}$ of glucose per minute under the above reaction conditions.

The optimal $\mathrm{pH}$ of $\mathrm{L}_{\mathrm{cf}}$ was determined by measuring the hydrolytic activity at different $\mathrm{pH}$ conditions. The buffers $(50 \mathrm{mM})$ used for this assay contained sodium acetate buffers ( $\mathrm{pH} 4.5,5.0$ and 5.6), sodium phosphate buffers ( $\mathrm{pH} 5.9,6.4$ and 6.9), and Tris- $\mathrm{HCl}$ buffer ( $\mathrm{pH} 7.5$ and 8.0). The effect of the temperature was measured at $15-65{ }^{\circ} \mathrm{C}$ in $50 \mathrm{mM}$ sodium acetate buffer, at $\mathrm{pH}$ 5.6. The above enzymatic activity was tested under standard conditions. To determine the thermal stability of $\mathrm{L}_{\mathrm{cf}}$, the residual hydrolytic activity of $\mathrm{L}_{\mathrm{cf}}$ (dissolved in sodium acetate buffer $(50 \mathrm{mM}, \mathrm{pH} 5.6)$ ) after incubation at different temperatures $\left(4-70^{\circ} \mathrm{C}\right)$ for $15 \mathrm{~min}$ was measured. The effect of metal ions was determined by measuring the activity with different metal ions $\left(\mathrm{Mg}^{2+}, \mathrm{Ca}^{2+}, \mathrm{Mn}^{2+}, \mathrm{Cu}^{2+}, \mathrm{Zn}^{2+}, \mathrm{Fe}^{3+}\right.$, and EDTA) at $5 \mathrm{mM}$ in $50 \mathrm{mM}$ sodium acetate buffer, at pH 5.6. All the above assays were performed in triplicate.

\subsection{TLC Assay}

The products of $\mathrm{L}_{\mathrm{cf}}$ degradation of laminarin and laminarihexaose (Megazyme) were generated as described above. The reaction mixture $(200 \mu \mathrm{L})$ contained $0.1 \%(w / w)$ laminarin or laminarihexose dissolved in sodium acetate buffer $(50 \mathrm{mM}, \mathrm{pH} 5.6)$ and $20 \mu \mathrm{L}$ purified $\mathrm{L}_{\mathrm{cf}}$. At different times, $5 \mu \mathrm{L}$ of reaction mixture were taken for TLC analysis. Samples were spotted on silica gel $60 \mathrm{~F}_{254}$ plates (Merck, Darmatadt, Germany), and separated in a solvent of 1-butanol/acetic acid/water (2:1:1, v/v). To visualize the products, the plate was sprayed with a reagent containing $2 \mathrm{~g}$ of diphenylamine, $2 \mathrm{~mL}$ of aniline, $1 \mathrm{~mL}$ of $\mathrm{HCl}, 10 \mathrm{~mL}$ of $\mathrm{H}_{3} \mathrm{PO}_{3}$, and $100 \mathrm{~mL}$ of acetone, and was heated at $100{ }^{\circ} \mathrm{C}$ for $10 \mathrm{~min}$ [38].

\subsection{Transglycosylation Products Assay}

To explore the transglycosalating ability of $\mathrm{L}_{\mathrm{cf}}$, several acceptors, including methyl $\alpha$-D-glucopyranoside, methyl $\beta$-D-glucopyranoside, glycerol, D-sorbitol, ethanol, and L-serine, were involved in the transglycosylation reactions. Briefly, $\mathrm{L}_{\mathrm{cf}}(0.02 \mathrm{U})$ was added into the mixture containing laminarihexaose $(2 \mathrm{mg} / \mathrm{mL})$ and an acceptor $(2 \mathrm{mg} / \mathrm{mL})$ dissolved in sodium acetate buffer ( $25 \mathrm{mM}$, pH 5.6). Then, the resulting mixture $(200 \mu \mathrm{L})$ was incubated at $37^{\circ} \mathrm{C}$ for $5 \mathrm{~min}$. The reaction was terminated by the addition of an equal volume of $2.5 \%(v / v)$ aqueous ammonia. After centrifugation, the supernatant was collected and detected using positive ion electrospray ionization mass spectrometry (ESI-MS) (Agilent 6460 Triple Quad, Santa Clara, CA, USA).

Author Contributions: Conceptualization, Q.L. and W.L.; Investigation, Z.L.; Writing-Original draft preparation, Z.L. and Q.L.; Writing_-Review and editing, Q.L.; Funding acquisition, Q.L. and W.L. All authors have read and agreed to the published version of the manuscript.

Funding: This research was funded by the National Natural Science Foundation of China, grant number 41706151 and the National Key R\&D Program of China, grant number 2018YFC1406903.

Conflicts of Interest: The authors declare no conflict of interest.

\section{References}

1. Sova, V.V.; Pesentseva, M.S. Glycosidases of marine organisms. Biochemistry (Moscow) 2013, 78, 746-759. [CrossRef] [PubMed]

2. Kim, Y.W.; Kim, K.H. Anti-diabetic activity of beta-glucans and their enzymatically hydrolyzed oligosaccharides from Agaricus blazei. Biotechnol. Lett. 2005, 27, 483-487. [CrossRef] [PubMed] 
3. Hida, T.H.; Ishibashi, K. Cytokine induction by a linear 1,3-glucan, curdlan-oligo, in mouse leukocytes in vitro. Inflamm. Res. 2009, 58, 9-14. [CrossRef] [PubMed]

4. Shimizu, J.; Oka, M. Effects of a partially hydrolyzed curdlan on serum and hepatic cholesterol concentration, and cecal fermentation in rats. Int. J. Vitam. Nutr. Res. 2002, 72, 101-108. [CrossRef]

5. Klarzynski, O.; Plesse, B. Linear beta-1,3 glucans are elicitors of defense responses in tobacco. Plant. Physiol. 2000, 124, 1027-1038. [CrossRef]

6. Li, J.; Zhu, L. Purification and characterization of a new endo- $\beta-1,3$-glucanase exhibiting a high specificity for curdlan for production of $\beta$-1,3-glucan oligosaccharides. Food Sci. Biotechnol. 2014, 23, 799-806. [CrossRef]

7. Vuong, T.V.; Wilson, D.B. Glycoside hydrolases: Catalytic base/nucleophile diversity. Biotechnol. Bioeng. 2010, 107, 195-205. [CrossRef]

8. Abdul Manas, N.H.; MdIllias, R. Strategy in manipulating transglycosylation activity of glycosyl hydrolase for oligosaccharide production. Crit. Rev. Biotechnol. 2018, 38, 272-293. [CrossRef]

9. Cobucci-Ponzano, B.; Moracci, M. Glycosynthases as tools for the production of glycan analogs of natural products. Nat. Prod. Rep. 2012, 29, 697-709. [CrossRef]

10. Ilari, A.; Fiorillo, A. Crystal structure of a family 16 endoglucanase from the hyperthermophile Pyrococcus furiosus-structural basis of substrate recognition. FEBS J. 2009, 276, 1048-1058. [CrossRef]

11. Oda, M.; Inaba, S. Structural and thermodynamic characterization of endo-1,3-beta-glucanase: Insights into the substrate recognition mechanism. Biochim. Biophys. Acta Protein Proteom. 2018, 1866, 415-425. [CrossRef] [PubMed]

12. Jeng, W.Y.; Wang, N.C. Crystal structures of the laminarinase catalytic domain from Thermotoga maritima MSB8 in complex with inhibitors: Essential residues for beta-1,3- and beta-1,4-glucan selection. J. Biol. Chem. 2011, 286, 45030-45040. [CrossRef] [PubMed]

13. Labourel, A.; Jam, M. Structural and biochemical characterization of the laminarinase ZgLamCGH16 from Zobellia galactanivorans suggests preferred recognition of branched laminarin. Acta Crystallogr. D Biol. Crystallogr. 2015, 71, 173-184. [CrossRef]

14. Sun, L.; Gurnon, J.R. Characterization of a $\beta-1,3$-glucanase encoded by chlorella virus PBCV-1. Virology 2000, 276, 27-36. [CrossRef] [PubMed]

15. Kozhemyako, V.B.; Rebrikov, D.V. Molecular cloning and characterization of an endo-1,3- $\beta$-D-glucanase from the mollusk Spisula sachalinensis. Comp. Biochem. Physiol. B Biochem. Mol. Biol. 2004, 137, 169-178. [CrossRef]

16. Kovalchuk, S.N.; Bakunina, I.Y. An endo-(1 $\rightarrow$ 3)-beta-D-glucanase from the scallop Chlamys albidus: Catalytic properties, cDNA cloning and secondary-structure characterization. Carbohydr. Res. 2009, 344, 191-197. [CrossRef] [PubMed]

17. Kumagai, Y.; Ojima, T. Enzymatic properties and the primary structure of a beta-1,3-glucanase from the digestive fluid of the Pacific abalone Haliotis discus hannai. Comp. Biochem. Physiol. B. Biochem. Mol. Biol. 2009, 154, 113-120. [CrossRef]

18. Takeda, T.; Nakano, Y. Identification and enzymatic characterization of an endo-1,3- $\beta$-glucanase from Euglena gracilis. Phytochemistry 2015, 116, 21-27. [CrossRef]

19. Cai, L.Q.; Meng, J.H. Identification of a crustacean $\beta-1,3$-glucanase related protein as a pattern recognition protein in antibacterial response. Fish. Shellfish Immunol. 2018, 80, 155-164. [CrossRef]

20. Cecarini, V.; Cuccioloni, M. Identification of a Killer Toxin from Wickerhamomyces anomalus with $\beta$-Glucanase Activity. Toxins 2019, 11, 568. [CrossRef]

21. Takashima, T.; Taku, T. Crystal structure and biochemical characterization of CJP38, a beta-1,3-glucanase and allergen of Cryptomeria japonica pollen. Mol. Immunol. 2019, 116, 199-207. [CrossRef] [PubMed]

22. Kusaykin, M.I.; Belik, A.A. A new recombinant endo-1,3- $\beta$-D-glucanase from the marine bacterium Formosa algae KMM 3553, Enzyme characteristics and transglycosylation products analysis. World J. Microbiol. Biotechnol. 2017, 33, 40. [CrossRef] [PubMed]

23. Borriss, R.; Krah, M. Enzymatic synthesis of 4-methylumbelliferyl (1 $\rightarrow 3$ )- $\beta$-D-glucooligosaccharides-new substrates for $\beta$-1,3-1,4-D-glucanase. Carbohydr. Res. 2003, 338, 1455-1467. [CrossRef]

24. Zakharenko, A.M.; Kusaykin, M.I. Catalytic properties and amino acid sequence of endo- $1 \rightarrow 3-\beta$-D-glucanase from the marine mollusk Tapes literata. Biochemistry (Moscow) 2012, 77, 878-888. [CrossRef] [PubMed]

25. Pesentseva, M.S.; Kusaykin, M.I. Catalytic properties and mode of action of endo-(1 $\rightarrow 3)$ - $\beta$-D-glucanase and $\beta$-D-glucosidase from the marine mollusk Littorina kurila. Carbohydr. Res. 2008, 343, 2393-2400. [CrossRef] 
26. Zakharenko, A.M.; Kusaykin, M.I. Enzymatic and molecular characterization of an endo-1,3- $\beta$-D-glucanase from the crystalline styles of the mussel Perna viridis. Carbohydr. Res. 2011, 346, 243-252. [CrossRef]

27. Kumagai, Y.; Inoue, A. Preparation of $\beta$-1,3-glucanase from scallop mid-gut gland drips and its use for production of novel heterooligosaccharides. Fish. Sci. 2008, 74, 1127-1136. [CrossRef]

28. Lyu, Q.; Jiao, W. Proteomic analysis of scallop hepatopancreatic extract provides insights into marine polysaccharide digestion. Sci. Rep. 2016, 6, 34866. [CrossRef]

29. Kovalchuk, S.N.; Sundukova, E.V. Purification, cDNA cloning and homology modeling of endo-1,3-beta-D-glucanase from scallop Mizuhopecten yessoensis. Comp. Biochem. Physiol. B. Biochem. Mol. Biol. 2006, 143, 473-485. [CrossRef]

30. Genta, F.A.; Bragatto, I. Purification, characterization and sequencing of the major beta-1,3-glucanase from the midgut of Tenebrio molitor larvae. Insect Biochem. Mol. Biol. 2009, 39, 861-874. [CrossRef]

31. Labourel, A.; Jam, M. The beta-glucanase ZgLamA from Zobellia galactanivorans evolved a bent active site adapted for efficient degradation of algal laminarin. J. Biol. Chem. 2014, 289, 2027-2042. [CrossRef]

32. Nakajima, M.; Yamashita, T. A novel glycosylphosphatidylinositol-anchored glycoside hydrolase from Ustilago esculenta functions in beta-1,3-glucan degradation. Appl. Environ. Microbiol. 2012, 78, 5682-5689. [CrossRef]

33. Liu, Z.; Xiong, Y. Endo-beta-1,3-glucanase digestion combined with the HPAEC-PAD-MS/MS analysis reveals the structural differences between two laminarins with different bioactivities. Carbohydr. Polym. 2018, 194, 339-349. [CrossRef]

34. Tang, F.; Wang, L.X. Chemoenzymatic synthesis of glycoengineered IgG antibodies and glycosite-specific antibody-drug conjugates. Nat. Protoc. 2017, 12, 1702-1721. [CrossRef]

35. Kurakake, M.; Amai, Y. Characteristics of an beta-N-Acetylhexosaminidase from Bacillus sp. CH11, Including its Transglycosylation Activity. J. Food Sci. 2018, 83, 1208-1214. [CrossRef] [PubMed]

36. Yashiro, K.; Lowenthal, J.W. High-level production of recombinant chicken interferon-gamma by Brevibacillus choshinensis. Protein Expr. Purif. 2001, 23, 113-120. [CrossRef] [PubMed]

37. Lyu, Q.; Wang, S. Structural insights into the substrate-binding mechanism for a novel chitosanase. Biochem. J. 2014, 461, 335-345. [CrossRef]

38. Qin, Z.; Yang, S.; Zhao, L.; You, X.; Yan, Q.; Jiang, Z. Catalytic Mechanism of a Novel Glycoside Hydrolase Family 16 "Elongating" beta-Transglycosylase. J. Biol. Chem. 2017, 292, 1666-1678. [CrossRef] 